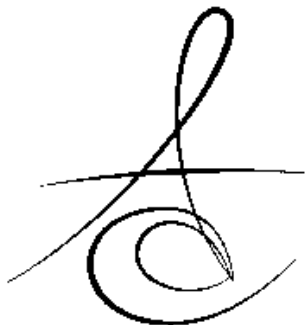

Makale Kodu/Article code: 1977

Makale Gönderilme tarihi: 25.11.2014

Kabul Tarihi: 19.12.2014

\section{OTOTRANSPLANTASYON: VAKA SERİSİ *}

\section{AUTOTRANSPLANTATION: CASE SERIES ${ }^{\star}$}

Arş. Gör. Dt. Nesrin SARUHAN*

Prof. Dr. Ümit ERTAŞ

\section{ÖZET}

$\mathrm{Bu}$ çalışmanın amacı, ototransplantasyon yapılan beş vaka ile birlikte, ototransplantasyonun başarı oranlarını, prognostik faktörlerini, komplikasyonlarını ve uygulanan farklı tedavi yöntemlerini sunmaktır.

Bir hastada bilateral olmak üzere, üst çenesinde gömülü kanini bulunan 3 hastanın gömülü kanin dişleri çekilerek ototransplante edildi. Diğer iki vakanın birinde çürük olan alt birinci büyük azı dişi diğerinde de alt ikinci büyük azı dişi çekilerek yerlerine gömülü durumda bulunan 20 yaş dişleri transplante edildi. Radyolojik ve klinik olarak takibi yapılan olgularda perioperatif veya postoperatif olarak herhangi bir komplikasyonla karşılaşılmadı.

Ototransplantasyon, gerekli prognostik faktörlere dikkat edildiğinde başarı oranı yüksek bir tedavi yöntemidir.

Anahtar Kelimeler: Transplantasyon; Gömülü diş

\section{ABSTRACT}

The purpose of this research is to present the five autotransplantation cases with respect to success rates, prognostic factors, complications and different treatment methods.

Three patients' impacted maxillary canines were extracted and autotransplanted - one of them bilaterally. Two patients underwent mandibular third molar autotransplantation to the sockets of decayed and therefore extracted first molar and second molar. Any perioperative or postoperative complication was seen at autotransplanted teeth which were followed up radiologically and clinically.

If the prognostic factors are taken into consideration, autotransplantation is a treatment method that has a high success rate.

Key Words: Transplantation; Impacted tooth

\section{GİRİ̧̧}

Ototransplantasyon; basit olarak, gömülü, yarı gömülü veya sürmüş dişlerin çekilip, aynı bireyin dişsiz bölgelerine, uygun bir donör diş varlığında, alıcı bölge soketinin cerrahi yöntemler ile hazırlanarak nakil edilmesi olarak tanımlanabilir. ${ }^{1,} 2$ İlk otojen molar ototransplantasyonu vaka raporları 1950'lerde bildirilmiş ve başarı oranı, transplantasyondan sonra kök gelişimi ve kök rezorpsiyonunun öngörülememesi nedeniyle yaklaşık \%50 seviyelerinde kalmıştır. ${ }^{1-3}$ Son yıllarda yapılan çalışmalarda ise bu oran \% 68-\% 92.5 seviyelerine kadar çıkmıştır. ${ }^{4-8}$

Bu vaka raporunda, 5 hastada yapılan molar ve kanin diş ototransplantasyonlarını ve kısa dönem takipleri ile beraber, ototransplantasyon tedavisinin başarı oranlarını, prognoz üzerine etki eden faktörlerini ve komplikasyon risklerini sunmaktayız.

\footnotetext{
*Atatürk Üniversitesi, Diş Hekimliği Fakültesi, Ağız, Diş ve Çene Cerrahisi AD

${ }^{\ddagger}$ Türk Oral ve Maksillofasiyal Cerrahi Derneği (TAOMS) 21. Uluslararası Bilimsel Kongresi $18-22$ Mayıs 2014, Bodrum-Türkiye, poster olarak sunulmuştur. (Olgu 4)

"1. Uluslararası Diş Hekimliği Sempozyumu 3-5 Ekim 2013, Rize-Türkiye, poster olarak sunulmuştur. (Olgu 2)
} 


\section{OLGU SUNUMLARI}

Diş eksikliği ve estetik problemler nedeniyle kliniğimize başvuran 5 hastanın klinik ve radyolojik muayeneleri yapıldı. Hastaların yapılan klinik muayenesinde biri bilateral olmak üzere 3 hastanın üst çenesinde kanin bölgesinde diş eksikliği olduğu, diğer iki hastanın birinin alt birinci büyük azı dişinde, diğerinde de alt ikinci büyük azı dişinde çürüğü olduğu görüldü. Hastaların yapılan radyolojik muayenelerinde, üst çenedeki diş eksiliğinin gömük kanin kaynaklı olduğu görüldü. Alt çenede çürük dişi bulunan hastaların da aynı segmentte gömük 20 yaş dişleri olduğu görüldü. Hastalara protetik tedavi ve ortodontik tedavi seçenekleri anlatıldı. Ortodontik tedaviyi uzun sürmesi ve maddi nedenlerle istemeyen hastalara gömülü kanin dişlerini takiben protetik olarak dişsiz alanların restorasyonları önerildi. Diğer dişlerinin preparasyonunu istemeyen hastalara ototransplantasyon tedavisi anlatıldı. Ototransplantasyon tedavisini tercih eden hastalara kliniğimizde tedavinin uygulanışı ve olası komplikasyon riskleri anlatılarak hastalardan bilgilendirme ve onam formu alındı. Lokal anestezi altında tam kalınlıklı flep kaldırıarak gömülü dişler atravmatik olarak çekildi. Dişler periodontal ligament ve Hertwig epitel kök kllıfının canlılı̆ını devam ettirmesi için \% 0.9 izotonik sodyum-klorür solüsyonunda bekletildi ve alıc soket transplante edilecek diş için cerrahi frezlerle hazırlandı. Transplante edilen dişler sokete yerleştirildi ve 3 dakika boyunca parmak basınc ile yerinde tutuldu. Transplante edilen dişlerin karşıt arkla oklüzal ilişkisi protez kliniğinde oklüzyon kağıtları ile kontrol edildi ve erken temaslardan kaçınıldı. Ototransplante dişler, stabilizasyon için komşuluğundaki dişlere iki hafta boyunca kompozit rezin ile splintlendi ve bir ay içerisinde kanal tedavileri yapıldı.

\section{OLGU 1}

20 yaşındaki erkek hasta mandibular sağ 47 numaralı dişindeki ağrı nedeniyle kliniğimize başvurdu. Gece ağrısından yakınan hastaya yapılan klinik ve radyolojik muayenede ilgili dişte derin dentin çürüğü saptandı(Resim 1A, 1B). 47 numaralı dişin çekimi yapıldı, aynı bölgedeki kök gelişimi tamamlanmamış 48 numaralı diş çekilerek (Resim 1C), transplante edildi.

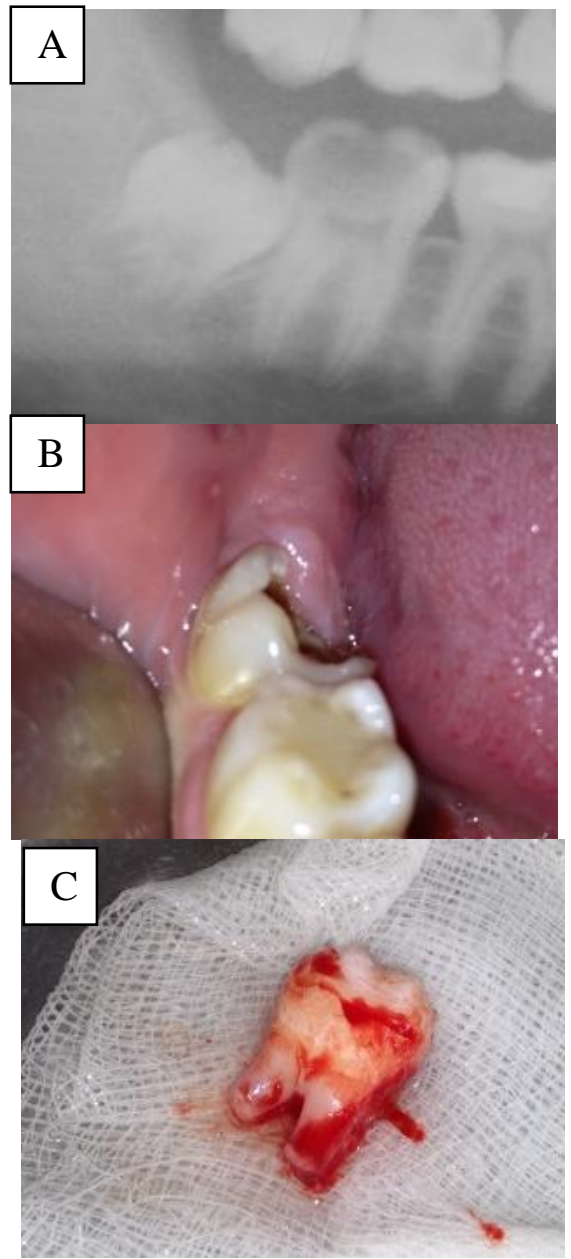

Resim 1. A: Kök gelişimi tamamlanmamış 48 numaralı gömülü üçüncü molar diş B: 47 numaralı dişte derin dentin çürüğü C: 0.9 izotonik sodyum-klorür solüsyonunda bekletilen transplante edilecek üçüncü molar diş

\section{OLGU 2}

24 yaşındaki kadın hasta maksilla sol bölgedeki dişsizlik şikayeti ile kliniğimize başvurdu. Yapılan klinik ve radyolojik muayenede hastanın 23 numaralı dişinin gömülü kaldığı tespit edildi (Resim 2A). 23 numaralı diş atravmatik olarak çekildi ve ototransplante edildi. (Resim 2B). 


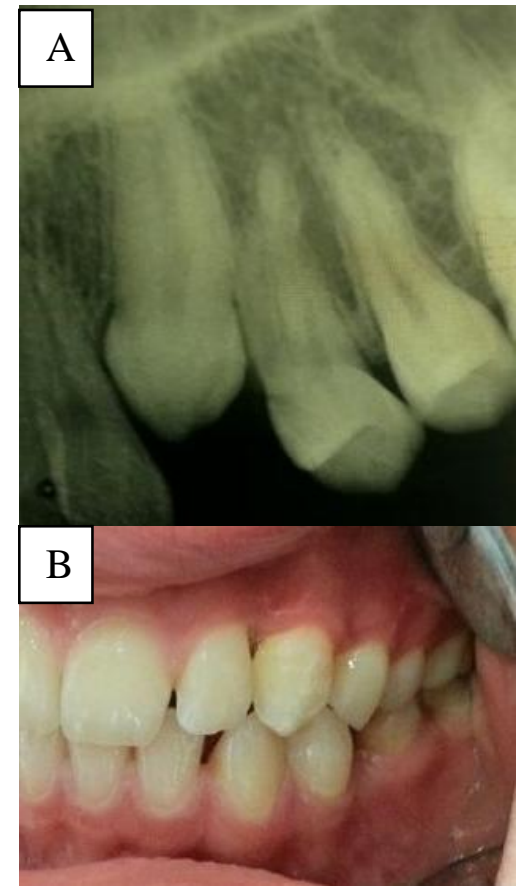

Resim 2: A: Gömülü sol maksiller kanin dişi için yeterli alan mevcuttu. B: Bir aylık kontrollerde bölgede herhangi bir patoloji görünmüyor.

\section{OLGU 3}

25 yaşındaki kadın hasta sağ mandibular birinci molar dişindeki ağıı nedeniyle kliniğimize başvurdu (Resim 3A). Yapılan radyolojik muayenede 46 numaralı dişin apeksinde lezyon tespit edildi. Bölgede yarı gömülü durumda kalmış, mukoza retansiyonlu 48 numaralı dişin transplantasyon için uygun olduğuna karar verildi ve hastaya transplantasyon tedavisi anlatıldı. Daha sonra 46 numaralı diş, bukkal kemiğe zarar vermemek için odontektomi yapılarak çekildi. Apikal granülom kürete edildi. Üçüncü molar bölgesine horizontal insizyon yapılarak, diş atravmatik çekildi ve sokete yerleştirildi (Resim 3B).

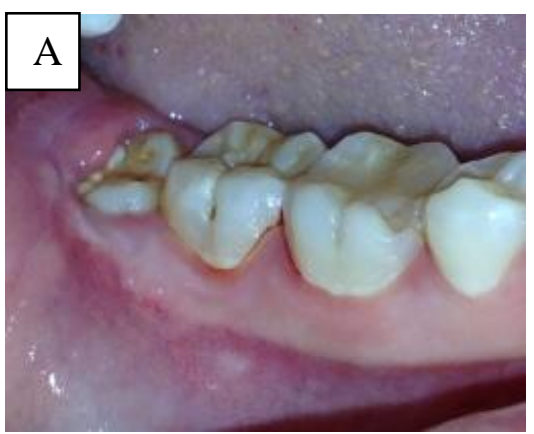

Resim 3: A: Restorasyonlu birinci molar diş ve transplante edilecek mukoza retansiyonlu üçüncü molar dişin ağız içi görünümü

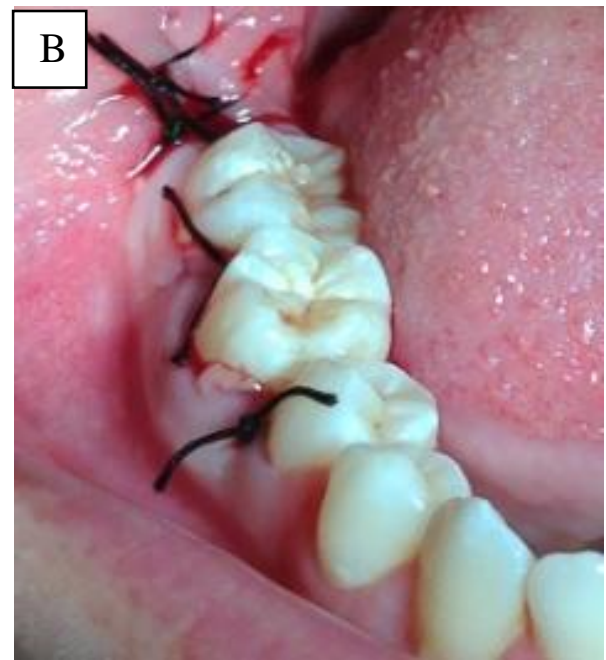

Resim 3: B: Transplante diş yerine yerleştirildikten sonra çevre dokular sütüre edildi.

\section{OLGU 4}

23 yaşında kadın hasta üst çene kanin bölgelerindeki bilateral diş eksiklikleri ve estetik problemlerle kliniğimize başvurdu. Yapılan klinik ve radyolojik muayenede, bilateral olarak maksiller kanin dişlerin gömülü olduğu görüldü. Hastaya ototransplantasyon tedavisi önerildi. Aynı seansta, sağ ve sol gömülü maksiller kanin dişler çekilerek ototransplante edildi. (Resim 4).

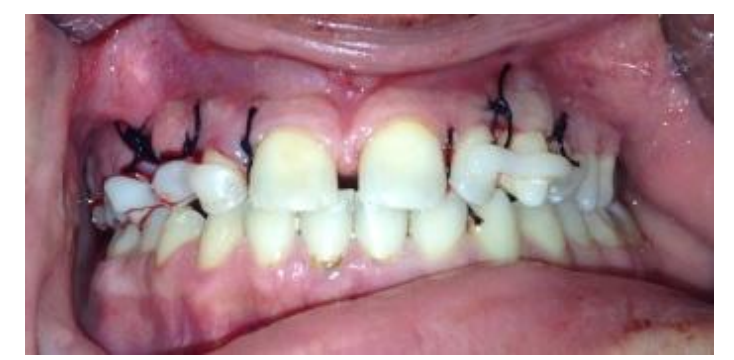

Resim 4. Ototransplante dişler iki hafta boyunca splintlendi.

\section{OLGU 5}

22 yaşındaki kadın hasta sol maksiller kanin diş bölgesindeki diş eksikliği ve estetik şikayet ile kliniğimize başvurdu. Yapılan klinik ve radyolojik muayenede, süt kanin diş kökü ile beraber gömülü 23 numaralı diş tespit edildi (Resim 5A). Süt diş kökü çekildi ve daimi gömülü kanin diş çekilerek alıcı sokete ototransplante edildi (Resim 5B). 


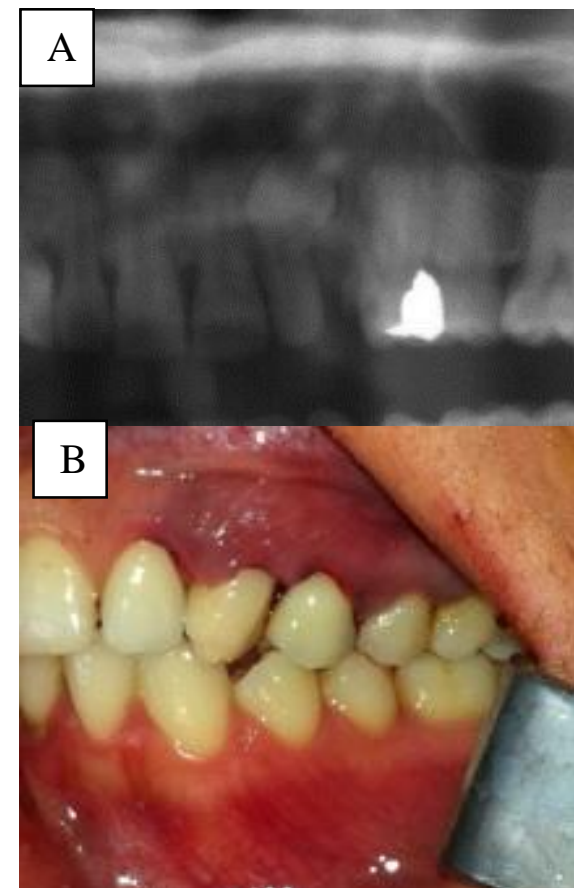

Resim 5. A: Gömülü sol maksiller kanin.B: Transplante edilen diş ile karşıt arktaki dişler arasında oklüzal uyum.

\section{TARTIŞMA}

Otojen diş transplantasyonu; otojen dişin, konjenital olarak eksik veya ektopik olarak sürmüş, kuron harabiyetli, periodontal hastalıklı, travma görmüş veya endodontik başarısızık nedeniyle çekilen bir dişin çekim soketine veya cerrahi olarak hazırlanmış alıcı bölgeye nakli olarak tanımlanabilir. Cross D. ve ark. ototransplantasyon tedavisinin düşünüleceği klinik hastaları dört grupta toplamışır;

1. Anterior maksiller dişlerin travma veya patoloji sonucu kaybı durumunda mandibular ikinci premolarların transplantasyonu.

2. Bir arkta hipodonti varken, diğer arkta diş çapraşıklığının bulunması.

3. Ektopik pozisyonlu dişlerin aynı arkta doğru yerine ototransplantasyonu.

4. Kötü prognozu olan birinci molarların, kök gelişimi sürmekte olan üçüncü molarlarla transplantasyonu. ${ }^{9}$

Sunulan 5 vakanın 3 'ünde ektopik durumdaki maksiller kanin dişler çekilerek aynı arktaki doğru yerlerine dişlerin ototransplantasyonu yapıldı. Diğer iki vakada ise kötü prognoza sahip alt birinci ve ikinci molar dişler çekilerek, kök gelişimi devam eden üçüncü molar dişler transplante edildi.
Czochrowska ve ark. ${ }^{4}$ na göre; ototransplantasyon tedavisinde başarı kriterleri; ilerleyici kök rezorpsiyonunun yokluğu, transplante edilmiş dişe komşu ve normal durumda sert ve yumuşak periodontal dokular ve kemik üzeri diş dokusunun kemik içi diş dokularına oranının 1'den az olmasıdır. ${ }^{4}$ Yapılan takiplerde vakaların hiçbirinde kök rezorpsiyonuyla veya periodontal problemlerle karşılaşılmadı.

Transplante edilen, kök gelişimini tamamlamamış kanin dişlerde diğer donör dişlere ve kök gelişimini tamamlamış dişlere göre daha fazla kök rezorpsiyonu geliştiği ve bu dişlerin daha fazla ankiloza uğradığı bildirilmiştir. Transplantasyon sırasındaki kök uzunlukları olması gerekenden $1 / 2$ ve $3 / 4$ uzunluğunda olan dişlerin anlamlı derecede yüksek başarı sağladıkları yine aynı araştırmada bildirilmiştir. ${ }^{10}$ Başarısız olgularda görülen kök rezorpsiyonu ve ankiloz yanında, kullanılan ototransplante dişin normal bir diş gibi kök kırığı, periodontal hastalık ve çürüme riski de tedavinin ana dezavantajları olarak görülmektedir. ${ }^{11}$

Azevedo P. ve ark. ${ }^{12}$ kök gelişimini tamamlamış ve transplante edilmiş kanin dişlerinde endodontik tedavi zamanlaması konulu araştımalarında, bir grupta diş transplante edildikten 15 gün sonra, diğer grupta ise dişler 40 gün sonra tedavi edilmiş̧ir. Sekiz hafta sonra, transplante edilmiş dişlerin uzun eksenine dik kesitlerle beraber, transplante edilmemiş dişlerden de kontrol amacıyla kesitler alınmıştır. Histolojik değerlerin iki grup arasında anlamlı bir fark göstermediği bildirilmiş ve endodontik tedavinin 40 güne kadar ertelenebileceği bildirilmiştir. Olgu 4 'te kanal tedavileri bilateral olarak 2 . hafta sonunda yapıldı, diğer olgularımızda ise bir ay sonunda endodontik tedavileri yapıldı.

Waikakul A. ve ark. ${ }^{13}$ otojen diş transplantasyonu sonrası alveol kemiğinde oluşan değişiklikleri incelemek amacıyla, geleneksel radyografik inceleme ve dijital subtraksiyon radyografisi yöntemlerini kullanarak, 54 hastada 54 üçüncü molar diş transplantasyonunu 1, 3, 6, 9 ve 12 aylık periyotlarda değerlendirmişlerdir. 48 dişte (\%89) üçüncü ayda tam kemik iyileşmesi, 34 dişte (\%63) altınca ayda lamina dura gelişimi gözlenmiştir. Araştırmacılar bu sonuçlara dayanarak, üçüncü molar diş transplantasyonlarının üç ay içinde çiğneme yükünü karşllayabileceği sonucuna varmıştır. ${ }^{13}$ Bu çalışma baz alınarak, transplante edilen

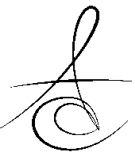


üçüncü molar dişlerde hastaya 3 . ay sonunda çiğneme yapabileceği söylendi.

Kök gelişimi henüz tamamlanmamış üçüncü molar dişlerin ototransplantasyonunda, farklı cerrahi tekniklerin, kök gelişimine etkisinin araştırıldığı bir çalışmada; 88 hastada kök gelişimi üç ile dördüncü seviye arasında olan 90 üçüncü molar diş transplante edilerek, dikey alveol mesafesi yetersizliklerinde serbest kemik grefti, yatay alveol kalınlığı yetersizliklerinde ise split osteotomi tekniği kullanıldığında, split osteotomi grubunun anlamlı bir şekilde kontrol grubundan daha kısa kök uzunluklarına sahip olduğu ve kök uzunluğunda daha az artışa neden olduğu bildirilmiştir. En iyi sonuçlar taze çekim soketlerine uyumlandırma dışında ek bir cerrahi teknik uygulanmayan kontrol grubunda görülmüştür. Kontrol grubu ile kemik otogreft grubu arasında veya split osteotomi grubu ile otogreft grubu arasında herhangi bir anlamlı ilişki bulunamamıştır. Araştırmacılar, kök gelişimi tamamlanmamış dişlerin ototransplantasyonunda, split ostetomi tekniğinin, pulpa revaskularizasyonu ve postoperatif kök gelişimine olumsuz etkisi olduğu sonucuna varmışlardır. ${ }^{14}$ Vakalarımızın hiçbirinde ek bir cerrahi işlem olarak split osteotomi veya kemik grefti uygulanmamıştır.

Bae J.H. ve ark. ${ }^{6}$ kök formasyonu tamamlanmış ve ortalama yaşı 38.5 (19-67 yaş aralığı) olan hasta grubunda 19 molar dişi ototransplante etmişler, ortalama 15 ay takip etmişler ve başarı oranını \%84 olarak bulmuşlardır. ${ }^{6}$ Vakaların 1 yıllık takiplerinde herhangi bir başarısızıkla karşılaşılmadı.

Konik ışınlı bilgisayarlı tomografi (CBCT) destekli ototransplantasyon cerrahisi planlama ve transfer tekniğinin, geleneksel cerrahi teknikle karşılaştırıldığı bir vaka kontrol çalışmasında, çalışma grubunda stereolitografik cerrahi rehberler ve transplante edilecek diş kopyaları hazırlanmışıı. CBCT destekli tekniğin, donör dişin ekstraoral koşullarda kalma ve alııı sokete uyumlandırma süresini azalttığı ve sonuç olarak geleneksel cerrahi yönteme göre daha az komplikasyona neden olduğu bildirilmiştir. ${ }^{15}$

\section{SONUÇ}

Ototransplantasyon, doğru endikasyonu olan hastada, biyolojik avantajlar açısından diş eksikliğinin en uygun tedavi şeklidir. Prognostik faktörlere dikkat edildiğinde başarı oranı oldukça yüksektir.

\section{KAYNAKLAR}

1. Apfel H. Autoplasty of enucleated prefunctional third molars. Journal of oral surgery $1950 ; 8: 289$ 96.

2. Miller HM. Transplantation; a case report. Journal of the American Dental Association 1950;40:237, illust.

3. Miller HM. Transplantation and reimplantation of teeth. Oral surgery, oral medicine, and oral pathology 1956;9:84-95.

4. Czochrowska EM, Stenvik A, Bjercke B, Zachrisson BU. Outcome of tooth transplantation: survival and success rates 17-41 years posttreatment. American journal of orthodontics and dentofacial orthopedics : official publication of the American Association of Orthodontists, its constituent societies, and the American Board of Orthodontics 2002;121:110-9; quiz 93.

5. Jonsson T, Sigurdsson TJ. Autotransplantation of premolars to premolar sites. A long-term follow-up study of 40 consecutive patients. American journal of orthodontics and dentofacial orthopedics : official publication of the American Association of Orthodontists, its constituent societies, and the American Board of Orthodontics 2004;125:668-75.

6. Bae JH, Choi YH, Cho BH, Kim YK, Kim SG. Autotransplantation of teeth with complete root formation: a case series. Journal of endodontics 2010;36:1422-6.

7. Mejare B, Wannfors K, Jansson L. A prospective study on transplantation of third molars with complete root formation. Oral surgery, oral medicine, oral pathology, oral radiology, and endodontics 2004;97:231-8.

8. Akkocaoglu M, Kasaboglu O. Success rate of autotransplanted teeth without stabilisation by splints: a long-term clinical and radiological followup. The British journal of oral \& maxillofacial surgery 2005;43:31-5.

9. Cross D, El-Angbawi A, McLaughlin P, Keightley A, Brocklebank L, Whitters J, McKerlie R, Cross L, Welbury R. Developments in autotransplantation of teeth. The surgeon : journal of the Royal Colleges of Surgeons of Edinburgh and Ireland 2013;11:49-55. 
10. Kallu R, Vinckier F, Politis C, Mwalili S, Willems G. Tooth transplantations: a descriptive retrospective study. International journal of oral and maxillofacial surgery 2005;34:745-55.

11. Sabuncuoglu FA, YIlmaz M, Uzun SA. Immediate autotransplantation of mandibular canine (a case report). Ataturk Univ. Dis Hek. Fak. Derg. J Dent Fac Atatürk Uni. 2012;5:20-3.

12. Azevedo PC, Moura CC, Zanetta-Barbosa D, Bernadineli N. Time of endodontic treatment in autogenic transplants of mature teeth: histological study in dogs. Oral surgery, oral medicine, oral pathology, oral radiology, and endodontics 2007;104:287-93.

13. Waikakul A, Punwutikorn J, Kasetsuwan J, Korsuwannawong S. Alveolar bone changes in autogenous tooth transplantation. Oral surgery, oral medicine, oral pathology, oral radiology, and endodontics 2011;111:e1-7.

14. Bauss O, Zonios I, Engelke W. Effect of additional surgical procedures on root development of transplanted immature third molars. International journal of oral and maxillofacial surgery 2008;37:730-5.

15. Shahbazian $M$, Jacobs $R$, Wyatt J, Denys $D$, Lambrichts I, Vinckier F, Willems G. Validation of the cone beam computed tomography-based stereolithographic surgical guide aiding autotransplantation of teeth: clinical case-control study. Oral surgery, oral medicine, oral pathology and oral radiology 2013;115:667-75.

\section{Yazışma Adresi}

Dt. Nesrin SARUHAN

Atatürk Üniversitesi, Diş Hekimliği Fakültesi, Ağız, Diş ve Çene Cerrahisi A D. Erzurum Fax: 0904422360945

TIf: 0904422311747

e-mail: dt_nesrin@yahoo.com 